\title{
Desempenho de Novilhos Simental Alimentados com Silagem de Sorgo, Cana-de-Açúcar e Palhada de Arroz Tratada ou não com Amônia Anidra
}

\author{
Gláucon César Cardoso ${ }^{1}$, Rasmo Garcia ${ }^{2}$, Alexandre Lima de Souza ${ }^{3}$, Odilon Gomes Pereira ${ }^{2}$, \\ Carlos Maurício Soares de Andrade ${ }^{4}$, Aureliano José Vieira Pires ${ }^{5}$, Fernando Salgado Bernardino ${ }^{6}$
}

\begin{abstract}
RESUMO - Avaliou-se o desempenho de novilhos alimentados com dietas contendo palhada de arroz amonizada, palhada de arroz + uréia, cana-de-açúcar + uréia e silagem de sorgo. Utilizaram-se 16 novilhos, Simental PO, com peso vivo médio de 400 kg, distribuídos em delineamento inteiramente casualizado. O experimento teve duração de 88 dias, sendo 15 de adaptação e 61 dias de avaliação, divididos em três períodos de 21 dias. O consumo total de MS, que variou de 7,1 a 10,0 kg/dia, diferiu entre as dietas, registrando-se maiores consumos para os animais que receberam dietas contendo palhada de arroz amonizada e silagem de sorgo, que, por sua vez, não diferiram entre si. A conversão alimentar não diferiu entre as diferentes dietas, registrando-se valor médio de 6,6. Observou-se maior ganho de peso para os animais que receberam palhada de arroz amonizada (1,59 kg/dia) em relação à palhada mais uréia (1,25 kg/dia). O efeito da amonização, melhorando o valor nutritivo da palhada de arroz, resultou em maior consumo voluntário deste volumoso e, conseqüentemente, em maior ganho diário de peso vivo dos animais, em relação à palhada de arroz não-tratada e suplementada com uréia.
\end{abstract}

Palavras-chave: composição bromatológica, consumo, conversão alimentar, ganho de peso

\section{Performance of Simental Steers Fed Sorghum Silage, Sugar Cane and Straw Rice Treated or not with Anhydrous Ammonia}

\begin{abstract}
The performance of steers fed diets using as roughage rice straw treated with anydrous ammonia, rice straw+urea, sugar cane + urea and sorghum silage were evaluated. Sixteen PO Simental steers, averaging $400 \mathrm{~kg}$ initial LW, were assigned to a completely randomized design. The experiment last 88 days, 15 days of adaptation and 61 experimental days, divided in three periods of 21 days. Total DM intake, that ranged from 7.1 to $10.0 \mathrm{~kg}$ /day, differ among treatments, where higher intakes were observed for the animals fed ammoniated rice straw and sorghum silage, that did not differ. Feed:gain ratio did not differ among different diets, and an average value of 6.6 was recorded. It was observed higherweight gain for the animals fed ammoniated rice straw (1.59 kg/day) in relation to the animals fed straw+urea ( $1.25 \mathrm{~kg} /$ day). The treatement with anydrous ammonia improved the rice straw nutritive value resulted in higher voluntary intake of this roughage and, consequently, in higher daily weight gain in relation to no treated rice straw and supplemented with urea.
\end{abstract}

Key Words: alimentary conversion, bromatologic composition, intake, weight gain

\section{Introdução}

Apesar de ter o segundo maior rebanho do mundo e das tecnologias já existentes, a bovinocultura de corte brasileira, em geral, apresenta modestos índices de produtividade. O desempenho dos animais em pastagens é razoável durante a estação chuvosa, observando-se na estação seca deficiência alimentar, causada pela baixa disponibilidade e qualidade do pasto, o que resulta em perda de peso dos animais. Esta situação contrastante que ocorre no período seco do ano é caracterizada por baixa taxa de ferti- lidade, alta taxa de mortalidade e abate tardio dos animais, além de animais com qualidade de carcaça inferior e de alto custo de produção. Estes, entre outros problemas, aliado à crescente demanda de alimentos, inclusive de carne bovina, sugerem mudanças em determinados segmentos da bovinocultura de corte brasileira.

A atividade de confinamento, de alto custo, poderá mostrar melhor viabilidade econômica se for utilizado volumoso de baixo custo, principalmente os resíduos de culturas anuais e resíduos industriais devidamente melhorados com tratamentos alternativos. Grande

\footnotetext{
${ }^{1}$ Zootecnista, M.Sc. E.mail: gccardoso@comnet1.com.br

2 Professor do DZO/UFV. E.mail: rgarcia@ufv.br

3 Zootecnista, D.Sc., Professor do Departamento de Ciências Biológicas/Zootecnia - UFMT. E.mail: alex-Is@pop.com.br

4 Zootecnista, D.Sc., Embrapa Acre. E.mail: mauricio@cpafac.embrapa.br

5 Professor do DTRZ/UESB.E.mail: aureliano@uesb.br

${ }^{6}$ Zootecnista, M.Sc. DZO/UFV. E.mail: fsbernadino@ibest.com.br
} 
produção de resíduos culturais tem forçado pesquisadores a avaliarem sistemas mais eficientes para sua utilização, que não sejam seu retorno ao solo, como adubo ou cobertura morta para o plantio direto.

Dos diferentes tipos de restos culturais, a palhada de arroz, resíduo gerado durante a colheita do grão de arroz, apresenta grande potencial de utilização como volumoso para ruminantes (Rahal et al. 1997), podendo ser utilizada como suplementação volumosa na época de escassez de forragens nas pastagens e também como volumoso exclusivo em confinamentos, em regiões ou propriedades em que este resíduo é abundante.

Entre os fatores que limitam a utilização dos restos de culturas, na sua forma in natura, para a alimentação de ruminantes, destacam-se a baixa disponibilidade de compostos nitrogenados, os elevados teores de carboidratos fibrosos, os altos teores de lignina e a baixa digestibilidade da matéria seca. Esses fatores, em conjunto, restringem o consumo desses volumosos, que, por sua vez, resultam em baixo desempenho animal (Van Soest, 1994; Jung \& Allen, 1995).

Dentre as diferentes formas de tratamentos químicos, físicos e biológicos existentes, a amonização de volumosos, utilizando amônia anidra ou uréia, tem sido uma alternativa bastante utilizada (Garcia \& Pires, 1998). Diversos trabalhos de pesquisa têm mostrado que a amonização de palhadas, capins em estádio avançado de maturidade e subprodutos da agroindústria, além de promover incrementos nos teores de compostos nitrogenados, reduz os teores de fibra, principalmente de hemicelulose, melhorando a digestibilidade dos materiais tratados, contribuindo para maior consumo e desempenho dos animais (Chermiti et al., 1994; Reis et al., 1995).

Diante do volume de palhada de arroz, aproximadamente 30 milhões de toneladas (FAO, 1997), que anualmente é produzido no Brasil e do grande potencial de aproveitamento deste volumoso na alimentação de bovinos, conduziu-se este experimento objetivando-se avaliar o consumo, a conversão alimentar e o desempenho de novilhos simental alimentados com dietas contendo silagem de sorgo, cana-de-açúcar e palhada de arroz tratada ou não com amônia anidra.

\section{Material e Métodos}

O experimento foi conduzido nas dependências da Companhia Mineira de Metais (CMM), empresa do Grupo Votorantin, na região de Paracatu, Noroeste do Estado de Minas Gerais, no período de abril a novembro de 1998. A pesquisa foi constituída de um período pré-experimental de 15 dias e um experimental de 63 dias, dividido em três períodos de 21 dias.

Foram utilizados 16 novilhos Simental PO, com peso vivo médio de $400 \mathrm{~kg}$, dispostos em baias individuais de $16 \mathrm{~m}^{2}$. Todos os animais receberam uma dose subcutânea de vermífugo à base de Ivermectina, de acordo com o peso individual, no início do período pré-experimental. Os tratamentos experimentais constituíram-se de: $\mathrm{T}_{1}$ : Palhada de arroz $+100 \mathrm{~g}$ de uréia; $\mathrm{T}_{2}$ : Palhada de arroz tratada com $3 \% \mathrm{NH}_{3} ; \mathrm{T}_{3}$ : Silagem de sorgo e $\mathrm{T}_{4}$ : Canade-açúcar +100 g de uréia.

Para os tratamentos 1 e 4, a uréia foi dissolvida em água e adicionada aos volumosos com uso de regador, na quantidade de 100 g de uréia por animal, fornecidos duas vezes ao dia. Nos tratamentos $1,2 \mathrm{e}$ 4, foram adicionados $50 \mathrm{~g}$ de gesso/dia, como fonte de enxofre, para equilibrar o balanço com o nitrogênio não-protéico, proveniente da uréia e amônia aplicadas.

A palhada de arroz foi obtida após colheita do grão por colheitadeira automotriz, fazendo-se o corte das plantas a $10 \mathrm{~cm}$ acima do nível do solo. Após desidratação ao sol, a palhada foi enfardada e armazenada em galpão, até o tratamento com amônia anidra. Os fardos possuíam tamanho médio de $30 \times 40 \times 70 \mathrm{~cm}$ e pesavam aproximadamente $8,6 \mathrm{~kg}$.

Duas medas de palhada de arroz foram construídas no campo contendo 310 fardos cada, totalizando, aproximadamente, $5.200 \mathrm{~kg}$ de feno. Na palhada tratada com amônia anidra, foi adicionada, com auxílio de regador, oito litros de água para cada $100 \mathrm{~kg}$ de forragem, para elevar o teor de umidade para próximo de $25 \%$ e propiciar melhor eficiência do processo de amonização (Schneider \& Flachowsky, 1990). Para evitar vazamento de amônia durante a aplicação e durante o período de armazenamento, que foi de oito semanas, as medas foram cobertas com lona plástica.

Para aplicação da amônia anidra, foram utilizados botijões com capacidade de 80 kg de peso líquido, cuja quantidade aplicada foi controlada pela diferença de pesos inicial e final dos botijões, colocados na posição invertida e apoiados em um suporte sobre uma balança para facilitar a saída de amônia. A conexão entre o cilindro e os pontos de aplicação nas medas foi feita com mangueiras plásticas de alta resistência. Dentro das medas foram colocados canos de PVC com $3 / 4$ de polegada de diâmetro, que foram perfurados ao meio com diâmetros de $0,5 \mathrm{~cm}$, a cada $15 \mathrm{~cm}$, em toda a sua

R. Bras. Zootec., v.33, n.6, p.2132-2139, 2004 (Supl. 2) 
extensão. Estes tubos foram dispostos entre os fardos de modo a possibilitar difusão rápida e uniforme da amônia ao longo da meda. A quantidade de amônia aplicada foi de 3\% em base da MS da palhada de arroz.

A palhada amonizada foi retirada da meda pelo menos 24 horas antes de ser fornecida aos animais, para que pudesse perder odor característico da amônia por aeração e evitar a restrição de consumo pelos animais.

O sorgo (híbrido BR-601) foi colhido quando os grãos apresentavam no estágio de farináceo duro, utilizando-se ensiladeiras móveis de acoplamento lateral ao trator e transportado em carretas graneleiras até o local de ensilagem. Para confecção das silagens, foram utilizados quatro silos tipo superfície, com capacidade de $50 \mathrm{t}$ cada, sendo a silagem compactada por tratores.

A alimentação volumosa foi fornecida ad libitum em dois tratos diários, às $7 \mathrm{~h} 30$ e 16h30, permitindo-se $10 \%$ de sobras. O concentrado (4 kg com $16 \%$ de PB) em todos os tratamentos foi oferecido aos animais duas vezes ao dia - metade na alimentação da manhã e metade na alimentação da tarde. A mistura entre volumoso e concentrado foi feita no cocho, no momento da alimentação. O concentrado utilizado no experimento foi composto por 73,5\% de milho moído, 23,5\% de farelo de soja e 3,0 kg de mistura mineral.

As pesagens dos animais foram realizadas ao início e ao final de cada período experimental, sempre pela manhã, às $7 \mathrm{~h} 30$. Na tarde que antecedia a pesagem dos animais, todo o alimento existente nos cochos era removido, para assegurar jejum de 14 horas.

Todo o alimento fornecido foi pesado diariamente e o consumo em cada baia, anotado individualmente. A amostragem e quantificação das sobras foram realizadas diariamente para os tratamentos com silagem de sorgo e com cana-de-açúcar, e semanalmente para os tratamentos envolvendo palhada de arroz. Ao fim de cada período, agruparam-se estas amostras obtendo-se uma amostra composta para cada unidade experimental.

Todas as amostras foram posteriormente analisadas no Laboratório de Nutrição Animal do Departamento de Zootecnia da UFV. Com a finalidade de não perder o nitrogênio proveniente da amonização, realizou-se a pré-secagem de todas as amostras por liofilização. Em seguida, procedeu-se ao processamento das amostras em moinho tipo "Willey”, utilizando-se peneira de 20 "mesh", e ao posterior acondicionameto em vidros identificados até o momento das análises bromatológicas.

As análises de matéria seca (MS), nitrogênio total (NT), fibra em detergente neutro (FDN), fibra em detergente ácido (FDA), lignina, celulose, cinza, nitrogênio insolúvel em detergente neutro (NIDN), nitrogênio insolúvel em detergente ácido (NIDA) e a digestibilidade in vitro da matéria seca (DIVMS) foram realizadas segundo os procedimentos descritos por Silva \& Queiroz (2002). Para determinação da DIVMS, utilizou-se o método de uma etapa (48 horas).

O delineamento utilizado foi o inteiramente casualizado, com quatro tratamentos e quatro repetições. Na comparação das médias, utilizou-se o teste Tukey, a 5\% de significância. As análises estatísticas foram realizadas pelo o Programa SAEG, versão 7.1 (UFV, 1997).

\section{Resultados e Discussão}

Os resultados da análise bromatológica dos volumosos e do concentrado são apresentados na Tabela 1. O teor de PB da palhada de arroz não-amonizada (7,2\%) está próximo dos valores encontrados na literatura para este volumoso (Ferreira, et al., 1990). O tratamento deste material com 3\% de amônia anidra (base MS) elevou o seu teor de PB para $15,5 \%$, resultando incremento de $115 \%$. Não se verificou, por meio de observações visuais, formação de bolores ou qualquer sinal de perda da palhada, amonizada ou não, que pudessem desenvolver comportamento de rejeição pelos animais.

Além dos baixos teores de PB registrados para a palhada de arroz e cana-de-açúcar, deve-se salientar que boa parte dos compostos nitrogenados destes volumosos encontrava-se ligada à parede celular, na forma de nitrogênio insolúvel em detergente neutro e de nitrogênio insolúvel em detergente ácido, como apresentado na Tabela 1. O nitrogênio insolúvel em detergente neutro, mas solúvel em detergente ácido, é digestível, sendo, porém, de lenta degradação no rúmen, enquanto o nitrogênio retido na forma de NIDA é praticamente indigestível, estando geralmente associado à lignina e a outros compostos de difícil degradação (Van Soest, 1994).

Quanto aos constituintes da parede celular, observou-se que a palhada de arroz amonizada apresentou menores teores de fibra em detergente neutro 
Tabela 1 - Composição bromatológica e digestibilidade in vitro da matéria seca (DIVMS) da palhada de arroz, palhada de arroz amonizada, silagem de sorgo e cana-de-açúcar

Table 1 - Chemical bromatologic and in vitro dry matter digestibility (IVDMD) of rice straw, rice straw ammoniated, sorghum silage and sugar cane

\begin{tabular}{|c|c|c|c|c|}
\hline \multirow[t]{2}{*}{$\begin{array}{l}\text { Itens } \\
\text { Items }\end{array}$} & \multicolumn{4}{|c|}{$\begin{array}{l}\text { Volumosos } \\
\text { Roughages }\end{array}$} \\
\hline & $\begin{array}{c}\text { Palhada de arroz } \\
\text { Rice straw }\end{array}$ & $\begin{array}{l}\text { Pallhada de arroz amonizada } \\
\text { Ammoniated rice straw }\end{array}$ & $\begin{array}{l}\text { Silagem de sorgo } \\
\text { Sorghum silage }\end{array}$ & $\begin{array}{l}\text { Cana-de-açúca } \\
\text { Sugar cane }\end{array}$ \\
\hline $\begin{array}{l}\text { Matéria seca \% } \\
\text { Dry matter \% }\end{array}$ & 80,7 & 78,1 & 25,1 & 29,9 \\
\hline $\begin{array}{l}\text { Proteína bruta }{ }^{1} \\
\text { Crude protein }{ }^{1}\end{array}$ & 7,2 & 15,5 & 6,9 & 2,6 \\
\hline $\begin{array}{l}\text { NIDN }^{2} \\
\text { NDIN }^{2}\end{array}$ & 32,8 & 49,51 & 37,2 & 55,47 \\
\hline $\begin{array}{l}\text { NIDA }^{2} \\
\text { ADIN }^{2}\end{array}$ & 11,67 & 12,23 & 15,75 & 26,89 \\
\hline $\begin{array}{l}\text { Fibra em detergente neutro }{ }^{1} \\
\text { Neutral detergent fiber }^{1}\end{array}$ & 77,3 & 74,0 & 73,6 & 67,2 \\
\hline $\begin{array}{l}\text { Fibra em detergente ácido }{ }^{1} \\
\text { Acid detergent fiber }^{1}\end{array}$ & 45,2 & 47,5 & 37,0 & 41,8 \\
\hline $\begin{array}{l}\text { Hemicelulose }^{1} \\
\text { Hemicellulose }^{1}\end{array}$ & 32,0 & 26,5 & 36,6 & 25,4 \\
\hline $\begin{array}{l}\text { Celulose }{ }^{1} \\
\text { Cellulose }^{1}\end{array}$ & 36,0 & 36,9 & 29,5 & 30,9 \\
\hline $\begin{array}{l}\text { Lignina }^{1} \\
\text { Lignin }^{1}\end{array}$ & 6,7 & 7,4 & 6,7 & 8,7 \\
\hline $\begin{array}{l}\text { DIVMS } \\
I V D M D\end{array}$ & 43,0 & 59,3 & 51,5 & 41,5 \\
\hline
\end{tabular}

1 Valores em porcentagem da matéria seca (Values in percent of dry matter).

2 Valores em porcentagem da proteína bruta (Values in percent of crude protein)

NIDN = nitrogênio insolúvel em detergente neutro (NDIN = neutral detergent insoluble nitrogen).

NIDA = nitrogênio insolúvel em detergente ácido ( $A D I N=$ acid detergent insoluble nitrogen).

(FDN) e de hemicelulose que a palhada nãoamonizada (Tabela 1). Estes resultados estão de acordo com a literatura, pois diversos autores (Ferreira et al., 1990; Paiva et al., 1995) têm mostrado que a amonização provoca reduções substanciais dos teores de FDN, em decorrência da solubilização parcial de hemicelulose.

Aumentos na DIVMS de volumosos tratados com amônia anidra são relacionados, geralmente, ao incremento no teor de nitrogênio total e à diminuição de hemicelulose, os quais promovem melhor atividade dos microrganismos do rúmen. Boa parte dos aumentos registrados para os valores de DIVMS pode ser explicada pela quebra das ligações ésteres existentes entre carboidratos estruturais e entre carboidratos estruturais e lignina (Goto et al., 1993).

Na Tabela 2, são apresentados os valores obtidos para o consumo médio diário de matéria seca (CMS), proteína bruta (CPB) e fibra em detergente neutro (CFDN), nos diferentes tratamentos. Como o concentrado foi fornecido na quantidade de $4,0 \mathrm{~kg} / \mathrm{dia}$, com base na matéria natural, para os diferentes tratamentos, o consumo do concentrado não diferiu $(\mathrm{P}>0,05)$ entre os tratamentos, proporcionando, em média, 0,73\% PV de MS, 0,12\% PV de PB e $0,11 \%$ PV de FDN. Dessa forma, as diferenças no consumo total desses nutrientes ocorreram em função de seus consumos para os diferentes volumosos utilizados.

O consumo total de MS, que variou de 7,1 a $10,0 \mathrm{~kg} / \mathrm{dia}$, diferiu $(\mathrm{P}<0,05)$ entre os tratamentos, registrando-se maiores valores para os animais que receberam rações com palhada de arroz tratada com amônia anidra e para aqueles que receberam silagem de sorgo, que, por sua vez, não diferiram entre si $(\mathrm{P}>0,05)$. As diferenças no consumo de MS dos volumosos resultaram em diferentes proporções volumoso/concentrado na dieta dos animais. A participação do volumoso na MS total consumida variou de $52,2 \%$, para a cana + uréia, a $66,2 \%$, para a palhada de arroz amonizada. O CMS total da ração contendo palhada de arroz tratada com amônia superou em $18 \%$ àquele obtido para a ração à base de palhada

R. Bras. Zootec., v.33, n.6, p.2132-2139, 2004 (Supl. 2) 
2136 Desempenho de Novilhos Simental Alimentados com Silagem de Sorgo, Cana-de-Açúcar e Palhada de Arroz...

Tabela 2 - Consumos médios diários de matéria seca, proteína bruta e fibra em detergente neutro, por novilhos Simental confinados

Table 2 - Average intakes of dry matter, crude protein and neutral detergent fiber by fedlot Simental steers

\begin{tabular}{|c|c|c|c|c|}
\hline \multirow[t]{2}{*}{$\begin{array}{l}\text { Consumo } \\
\text { Intake }\end{array}$} & \multicolumn{4}{|c|}{$\begin{array}{l}\text { Tratamentos } \\
\text { Treatments }\end{array}$} \\
\hline & $\begin{array}{c}\text { Palhada de arroz } \\
\text { amonizada } \\
\text { Ammoniated rice } \\
\text { straw }\end{array}$ & $\begin{array}{c}\text { Palhada de arroz } \\
\text { + uréia } \\
\text { Rice straw }+ \\
\text { urea }\end{array}$ & $\begin{array}{l}\text { Silagem de sorgo } \\
\text { Sorghum silage }\end{array}$ & $\begin{array}{c}\text { Cana-de-açúcar } \\
\text { + uréia } \\
\text { Sugar cane+ urea }\end{array}$ \\
\hline & \multicolumn{4}{|c|}{$\begin{array}{l}\text { Consumo de matéria seca } \\
\text { Dry matter intake }\end{array}$} \\
\hline $\begin{array}{l}\text { Total (kg/dia) } \\
\text { Total (kg/day) }\end{array}$ & 10,00 a & $8,21 \mathrm{~b}$ & 9,35 a & $7,10 \mathrm{c}$ \\
\hline $\begin{array}{l}\text { Total }(\% \text { PV) } \\
\text { Total }(\% \text { LW) }\end{array}$ & $2,04 \mathrm{a}$ & $1,78 \mathrm{ab}$ & $2,02 \mathrm{a}$ & $1,61 \mathrm{~b}$ \\
\hline $\begin{array}{l}\text { Concentrado }(\% \mathrm{PV}) \\
\text { Concentrate }(\% L W)\end{array}$ & 0,69 a & $0,74 \mathrm{a}$ & $0,74 \mathrm{a}$ & $0,77 \mathrm{a}$ \\
\hline \multicolumn{5}{|l|}{ Roughage (\% LW) } \\
\hline & \multicolumn{4}{|c|}{$\begin{array}{l}\text { Consumo de proteína bruta } \\
\text { Crude protein intake }\end{array}$} \\
\hline $\begin{array}{l}\text { Total (kg/dia) } \\
\text { Total (kg/day) }\end{array}$ & $1,58 \mathrm{a}$ & $1,16 b$ & $0,96 \mathrm{c}$ & $0,88 \mathrm{~d}$ \\
\hline $\begin{array}{l}\text { Total }(\% \text { PV }) \\
\text { Total }(\% \quad L W)\end{array}$ & $0,32 \mathrm{a}$ & $0,25 b$ & $0,21 \mathrm{c}$ & $0,20 \mathrm{c}$ \\
\hline $\begin{array}{l}\text { Concentrado }(\% \mathrm{PV}) \\
\text { Concentrate }(\% \quad L W)\end{array}$ & $0,112 \mathrm{a}$ & $0,119 a$ & $0,120 \mathrm{a}$ & $0,125 \mathrm{a}$ \\
\hline $\begin{array}{l}\text { Volumoso (\% PV) } \\
\text { Roughage (\% LW) }\end{array}$ & $0,208 \mathrm{a}$ & 0,133b & $0,090 \mathrm{c}$ & $0,076 \mathrm{c}$ \\
\hline & \multicolumn{4}{|c|}{$\begin{array}{l}\text { Consumo de fibra em detergente neutro } \\
\text { Neutral detergent fiber intake }\end{array}$} \\
\hline $\begin{array}{l}\text { Total (kg/dia) } \\
\text { Total (kg/day) }\end{array}$ & $5,47 \mathrm{a}$ & 4,25 c & 4,89b & $3,03 \mathrm{~d}$ \\
\hline $\begin{array}{l}\text { Total }(\% \text { PV) } \\
\text { Total }(\% \text { LW) }\end{array}$ & $1,11 \mathrm{a}$ & $0,92 \mathrm{~b}$ & $1,06 \mathrm{a}$ & 0,69 c \\
\hline $\begin{array}{l}\text { Concentrado }(\% \mathrm{PV}) \\
\text { Concentrate }(\% L W)\end{array}$ & 0,108 a & 0,115 a & 0,116a & $0,121 \mathrm{a}$ \\
\hline $\begin{array}{l}\text { Volumoso (\% PV) } \\
\text { Roughage }(\% \quad L W)\end{array}$ & $1,00 \mathrm{a}$ & $0,81 \mathrm{~b}$ & $0,94 \mathrm{a}$ & $0,57 \mathrm{c}$ \\
\hline
\end{tabular}

Médias, na linha, seguidas de letras diferentes são diferentes $(P<0,05)$ pelo teste Tukey.

Means within a row followed by different letters differ $(P<.05)$ by Tukey test.

mais uréia, o que pode ser atribuído ao efeito da amonização, melhorando o valor nutritivo deste volumoso, obtendo-se redução dos teores de alguns constituintes da parede celular e incremento da DIVMS.

Okamoto \& Miyazaky (1990), utilizando palhada de arroz, amonizada ou não, como única fonte de volumoso na alimentação de carneiros, concluíram que a amonização acelerou a redução no tamanho das partículas durante a mastigação e digestão ruminal. Essas mudanças contribuíram para aumentar a taxa de passagem do alimento, elevando, por conseqüência, o consumo de matéria seca.

Os consumos totais de $\mathrm{PB}$, que variaram de
0,88 kg/dia (cana-de-açúcar + uréia) a 1,58 kg/dia (palhada amonizada), diferiram entre os tratamentos, registrando-se maiores ingestões nos animais alimentados com palhada tratada com amônia (Tabela 2), em decorrência do maior teor protéico deste volumoso, visto que a contribuição da proteína bruta proveniente do concentrado foi a mesma para os quatro tratamentos.

O maior consumo de PB nos animais recebendo palhada + uréia, em relação à silagem de sorgo, deve-se à suplementação da palhada com uréia, já que os dois volumosos possuíam teores de PB semelhantes. A participação dos volumosos no consumo total de PB

\section{R. Bras. Zootec., v.33, n.6, p.2132-2139, 2004 (Supl. 2)}


variou de $38,0 \%$, quando o volumoso fornecido foi a cana-de-açúcar + uréia, a $65,0 \%$, quando o volumoso foi a palhada amonizada. Mesmo com a suplementação da palhada de arroz não-tratada com uréia (100 g/dia), o consumo de PB proporcionado pela palhada de arroz amonizada foi ainda 56\% superior ao deste volumoso.

O consumo total de fibra em detergente neutro (FDN), em relação ao PV, que variou de 0,69 (cana + uréia) a 1,11\% PV (palhada amonizada) diferiu $(\mathrm{P}<0,05)$ entre os tratamentos (Tabela 2$)$, registrando-se menor consumo para aqueles animais que receberam cana-de-açúcar mais uréia como fonte de volumoso. Essas diferenças no consumo de FDN não parecem ser resultantes das diferenças nos teores de FDN dos volumosos, mas sim das diferenças quanto à qualidade da FDN desses volumosos. A cana-de-açúcar, embora apresente baixo teor de FDN em relação aos demais volumosos, a baixa taxa e extensão de degradação de sua fração fibrosa, provavelmente explique o menor consumo de FDN da ração suplementada com cana-de-açúcar mais uréia. O baixo consumo voluntário da cana-de-açúcar está associado à baixa degradação de sua fibra no rúmen, o que provoca acúmulo de fibra neste compartimento, limitando, assim, o consumo pelo enchimento (Orskov \& Hovell, 1978, citados por Pereira, 1995). De fato, vários trabalhos mostram baixa degradação da fra- ção fibrosa da cana-de-açúcar. Aroeira et al. (1993) verificaram que a degradação do conteúdo de FDN deste volumoso foi de apenas $43,7 \%$ após 72 horas de incubação ruminal.

Na Tabela 3, são apresentadas as médias dos pesos inicial e final dos animais e os resultados obtidos para ganho em peso e conversão alimentar e protéica das rações fornecidas. Observou-se maior $(\mathrm{P}<0,05)$ ganho de peso diário para os animais que receberam palhada amonizada, em relação à palhada mais uréia e cana-de-açúcar (Tabela, 3), sendo que estas duas últimas não diferiram da silagem de sorgo, que apresentou ganhos semelhantes $(\mathrm{P}>0,05)$ aos obtidos para a palhada amonizada.

O ganho diário de peso vivo dos animais alimentados com palhada amonizada foi $27,8 \%$ superior ao obtido pelos animais alimentados com palhada + uréia, valor muito próximo aos 30\% encontrados quando se comparou o consumo de MS destes volumosos. Portanto, o efeito da amonização, melhorando o valor nutritivo da palhada tratada, particularmente sua DIVMS, resultou em maior consumo deste volumoso e, conseqüentemente, em melhor desempenho dos animais. Melhores desempenhos de animais alimentados com forragens tratadas com amônia anidra, em relação a animais alimentados com forragens suplementados com uréia, também foram relatados por Saenger et al. (1982), Klee

Tabela 3 - Médias dos pesos vivos inicial e final, ganhos de peso vivo total e diário, conversão alimentar (CA) de novilhos Simental confinados

Table 3 - Average initial and final liveweight, total and daily weight gain and feed conversion (FC) by Simental steers feedlot

\begin{tabular}{|c|c|c|c|c|}
\hline \multirow[t]{2}{*}{$\begin{array}{l}\text { Itens } \\
\text { Items }\end{array}$} & \multicolumn{4}{|c|}{$\begin{array}{l}\text { Tratamentos } \\
\text { Treatments }\end{array}$} \\
\hline & $\begin{array}{c}\text { Palhada de arroz } \\
\text { amonizada } \\
\text { Ammoniated rice } \\
\text { straw }\end{array}$ & $\begin{array}{c}\text { Palhada de arroz } \\
\text { + uréia } \\
\text { Rice straw }+ \\
\text { urea }\end{array}$ & $\begin{array}{l}\text { Silagem de sorgo } \\
\text { Sorghum silage }\end{array}$ & $\begin{array}{c}\text { Cana-de-açúcar } \\
\text { + uréia } \\
\text { Sugar cane+ urea }\end{array}$ \\
\hline $\begin{array}{l}\text { Peso vivo inicial (kg) } \\
\text { Liveweight initial }(\mathrm{kg})\end{array}$ & 439,5 & 419,0 & 412,7 & 410,7 \\
\hline $\begin{array}{l}\text { Peso vivo final }(\mathrm{kg}) \\
\text { Liveweight final }(\mathrm{kg})\end{array}$ & 539,8 & 497,5 & 502,0 & 481,0 \\
\hline $\begin{array}{l}\text { Ganho de peso total (kg) } \\
\text { Weight gain }(\mathrm{kg})\end{array}$ & 100,3 & 78,5 & 89,3 & 70,3 \\
\hline $\begin{array}{l}\text { Ganho de peso diário (kg/dia) } \\
\text { Daily weight gain (kg/day) }\end{array}$ & $1,59 \mathrm{a}$ & $1,25 b$ & $1,42 \mathrm{ab}$ & $1,11 \mathrm{~b}$ \\
\hline $\begin{array}{l}\text { CA (kg de MS/kg de ganho) } \\
F C(\mathrm{~kg} \mathrm{DM} / \mathrm{kg} \text { gain) }\end{array}$ & $6,36 \mathrm{a}$ & $6,64 \mathrm{a}$ & $6,71 \mathrm{a}$ & $6,42 \mathrm{a}$ \\
\hline
\end{tabular}

Médias, na linha, seguidas de letras diferentes são diferentes $(P<0,05)$ pelo teste Tukey.

Means within a row followed by different letters differ $(P<.05)$ by Tukey test.

R. Bras. Zootec., v.33, n.6, p.2132-2139, 2004 (Supl. 2) 
\& Vidal (1986) e Teixeira (1990), utilizando palhada de milho, palhada de trigo e palhada de milho mais sabugo e capim-elefante picado, respectivamente.

De modo geral, os elevados ganhos de peso vivo verificados neste experimento (superiores a $1,1 \mathrm{~kg} /$ dia) podem ser atribuídos à elevada quantidade de concentrado fornecida aos animais (4,0 kg/dia, com base na matéria natural), que representou de 33,8 a 47,8\% da MS consumida, e, também, ao alto potencial genético dos animais utilizados no experimento, novilhos PO da raça Simental.

A quantidade de matéria seca consumida diariamente pelo animal é o principal fator nutricional que controla a produção animal, quando o alimento em excesso é oferecido (Minson \& Wilson, 1994). Como as diferenças para o consumo total de MS, registradas neste experimento, foram proporcionadas pelas diferenças no consumo de MS da palhada de arroz amonizada, palhada de arroz não-amonizada, canade-açúcar e silagem de sorgo, pode-se inferir que parte das diferenças verificadas para o ganho de peso vivo pode ter ocorrido em função dos fatores que restringiram o consumo de MS destes volumosos. A não-constatação de diferenças entre os tratamentos, quanto à conversão alimentar (Tabela 3), parece confirmar esta hipótese.

\section{Conclusões}

O tratamento da palhada de arroz com amônia anidra proporciou maior consumo voluntário de MS e ganho diário de peso vivo dos animais, equiparando-se a silagem de sorgo e superior à palhada não-amonizada e cana-de-açúcar, mostrando ser uma alternativa que pode ser empregada com sucesso em programas de engorda de bovinos.

\section{Literatura Citada}

AROEIRA, L.J.M.; SILVEIRA, M.I.; LIZIEIRE, R.S. et al. Digestibilidade balanço de nitrogênio e concentração de amônia no rúmen de novilhos mestiços alimentado com cana-de-açúcar e uréia mais farelos de arroz ou algodão. Revista da Sociedade Brasileira de Zootecnia, v.22, n.6, p.893-901, 1993.

CHERMITI, A.; TELLER, E.; VANBELLE, M. et al. Effect of ammonia or urea treatment of straw on chewing behavior and ruminal digestion processes in non-lactating dairy cows. Animal Feed Science Technology, v.47, n.1/2, p.41-51, 1994.

FAO. Production Yearbook, Roma, v.51, n.142, p.64, 1997. (FAO Statistics Series, 142).
FERREIRA, J.Q.; GARCIA, R.; QUEIROZ, A.C. et al. Efeitos dos níveis de amônia anidra e dos períodos pós-tratamento sobre a qualidade da palha de arroz. Revista da Sociedade Brasileira de Zootecnia, v.19, n.1, p.39-43, 1990.

GARCIA, R.; PIRES, A.J.V. Tratamento de volumosos de baixa qualidade para utilização na alimentação de ruminantes. In: CONGRESSO NACIONAL DOS ESTUDANTES DE ZOOTECNIA, 1998, Viçosa, MG. Anais... Viçosa: AMEZ, 1998. p.33-61.

GOTO, M.; YOKOE, Y.; TAKABE, K. et al. Effects of gaseous ammonia on chemical and strutctural features of cell walls in spring barle straw. Animal Feed Science and Technology, v.40, n.2/3, p.207-221, 1993.

JUNG, H.G.; ALLEN, M.S. Characteristics of plant cell walls affecting intake and digestibility of forages by ruminants. Journal of Animal Science, v.73 n.2, p.2774-2790, 1995.

KLEE, G.G.; VIDAL, A.V. Efectos del tratamiento con amoniaco anidro de la paja de trigo en los aumentos de peso y consumo de novillos holandeses. Agricultura Técnica Chile, v.46, n.1, p.3-8, 1986.

MINSON, D.J.; WILSON, J.R. Prediction of intake as an element of forage quality. In: FAHEY JR., G.C. (Ed.) Forage quality, evaluation and utilization. Lincoln: University of Nebraska, 1994. p.533-563.

OKAMOTO, M.; MIYAZAKI, H. Particule size reduction of reticulo-ruminal contents in sheep fed rice straw and ammoniated rice straw. Japanese Journal Zootecnia Science, v.61, n. 5, p.424-427, 1990.

PAIVA, J.A.J.; GARCIA, R.; QUEIROZ, A.C. et al. Efeitos dos níveis de amônia anidra e períodos de amonização sobre os teores dos constituintes da parede celular na palhada de milho (Zea mays L.). Revista da Sociedade Brasileira de Zootecnia, v.24, n.5, p.683-692, 1995.

PEREIRA, O.G. Valor nutritivo da cana-de-açúcar (Saccharum officinarum L.) sob as formas integral, sacharina e colmo desidratado, para bovinos e ovinos. Viçosa, MG: Universidade Federal de Viçosa, 1995. 114p. Tese (Doutorado em Zootecnia) - Universidade Federal de Viçosa, 1995.

RAHAL, A.; SINGH, A.; SINGH, M. Effect of urea treatment and composition on, and prediction of nutritive value of rice straw of different cultivars. Animal Feed Science and Technology, v.68, n.1/2, p.165-182, 1997.

REIS, R.A.; ANDRADE, P.; RODRIGUES, L.R.A. et al. Palha de arroz e feno de braquiária brizanta amonizados e suplementados com energia ou proteína na alimentação de bovinos. Revista da Sociedade Brasileira de Zootecnia, v.24, n.5, p.832-840, 1995.

SAENGER, P.F.; LEMENAGER, R.P.; HENDRIX, K.S. Anhydrous ammonia treatment of corn stover and its effects on digestibility, intake and performance of beef cattle. Journal of Animal Science, v.54, n.2, p.419-425, 1982.

SCHNEIDER, M.; FLACHOWSKY, G. Studies on ammonia treatment of whear straw: effects or level of ammonia, moisture content, treatment time and temperature on straw composition and degradation in the rumen of sheep. Animal Feed Science and Technology, v.29, n.3/4, p.252-264, 1990.

SILVA, D.J.; QUEIROZ, A.C. Análise de alimentos: métodos químicos e biológicos. 3.ed. Viçosa, MG: Universidade Federal de Minas Gerais, 2002. 235p. 
TEIXEIRA, J.R.C. Efeito da amônia anidra no valor nutritivo de palha de milho mais sabugo e do capim-elefante (Penninsetum purpureum Shum.) cv. Cameroom fornecidas a novilhos Nelore em confinamento. Viçosa, MG: Universidade Federal de Viçosa, 1990. 97p. Dissertação (Mestrado em Zootecnia) - Universidade Federal de Viçosa, 1990.

UNIVERSIDADE FEDERAL DE VIÇOSA - UFV. SAEG Sistema de análises estatísticas e genéticas. Versão 7.1. Viçosa, MG, 1997. 150p. (Manual do usuário)
Van SOEST, P.J. Nutritional ecology of the ruminant. Ithaca: Cornell University Press, 1994. 476p.

Recebido em: 25/08/03

Aceito em: 24/05/04 